\title{
Low-grade gliomas in children: tumor volume response to radiation
}

\section{Barbara J. Fisher, M.D., F.R.C.P.(C), Glenn S. Bauman, M.D., F.R.C.P.(C), Christopher E. Leighton, M.D., F.R.C.P.(C), Larry Stitt, M.Sc., J. Gregory Cairncross, M.D., F.R.C.P.(C), and David R. Macdonald, M.D., F.R.C.P.(C)}

Department of Radiation Oncology, Medical Oncology, and Biometry, London Regional Cancer Centre and University of Western Ontario, London, Ontario, Canada; Department of Clinical Neurological Sciences, University of Western Ontario, London, Ontario, Canada

Object. The authors conducted a retrospective review to examine and document the frequency, degree, and timing of the radiologically confirmed response to radiotherapy of low-grade gliomas in children.

Methods. Between 1963 and 1995, 80 patients 17 years of age or younger were referred to the London Regional Cancer Centre in London, Ontario, after diagnosis of a low-grade glioma. All patients underwent surgical resection or biopsy procedures and 47 underwent radiotherapy (40 postoperatively and seven at the time of tumor progression). Nineteen patients with residual measurable lesions who received radiation therapy were selected for volumetric analysis of tumor response to this treatment. The extent and timing of response to radiation were determined by the process of comparing postoperative, preirradiation computerized tomography (CT) scans with postirradiation, follow-up CT scans. For one patient the comparison was made by using serial magnetic resonance images.

Residual tumor was found on postoperative CT scans in all cases. The mean preradiotherapy tumor volume was $17.1 \mathrm{~cm}^{3}$, and the postradiotherapy volume was reduced to a mean of $11.5 \mathrm{~cm}^{3}$. A reduction in tumor was demonstrated in eight patients by the time of their first postirradiation follow-up CT scan and in two patients a slower reduction in volume over time was shown, bringing the total number of "responders" to 10 . In five of these 10 patients the tumor had shown a maximum response by the time of the first postirradiation CT scan; the median time to response was 3.3 months. A $25 \%$ or greater reduction in tumor volume was seen in eight (42\%) of the 19 patients. A $50 \%$ or greater reduction was noted in five (26\%) of the patients. A complete response was demonstrated at 7, 12, and 15 months, and 5 years, respectively, in four patients (21\%). One responder's tumor eventually increased in size after radiotherapy and he died of his disease.

The magnitude of the radiographically demonstrated response to radiation did not correlate significantly with clinical outcome (that is, survival or symptom improvement).

Conclusions. On the basis of this CT scan analysis of the response of low-grade gliomas in children to radiotherapy, the authors suggest that these lesions respond to radiation, as demonstrated by tumor shrinkage on serial imaging. Major or complete responses occur occasionally. However, low-grade gliomas in children mimic other benign brain tumors such as pituitary adenomas and meningiomas in that, although growth is frequently arrested after radiotherapy, residual tumor can persist for many years, illustrating that tumor shrinkage may not be a good measure of treatment efficacy. 
Nevertheless, radiation therapy can result in improvement of clinical symptomatology in association with or independent of visible tumor reduction. As radiation treatment techniques become increasingly conformal and because studies indicate that lower doses of radiation may be equally effective, improvement of symptoms may be an important consideration when weighing treatment options, particularly in patients with residual or unresectable disease.

\section{Key Words * low-grade glioma * radiation therapy * children}

Low-grade gliomas comprise the most common type of brain tumor in children. The role of radiation therapy in the management of low-grade gliomas remains controversial, although incompletely resected or recurrent low-grade gliomas are frequently treated with radiotherapy. Low-grade glioma cell lines demonstrate in vitro radiosensitivity,[23] and authors of retrospective clinical studies[11] have described radiotherapy as being effective in producing long-term survival and control of low-grade gliomas in children. However, the commonly held belief is that low-grade gliomas in the pediatric population, particularly pilocytic astrocytomas, are indolent and therefore, their size is unlikely to be affected by radiation. The response of these tumors in vivo as determined on radiological studies and the relationship of such response to clinical outcome have not been well documented.

This study is an attempt to analyze the patterns of the radiologically determined response of low-grade gliomas in children treated with radiotherapy to determine the extent and timing of such response.

\section{CLINICAL MATERIAL AND METHODS}

\section{Patient Selection and Treatment}

Between 1963 and 1995, 80 children (aged 3/4 17 years) in whom a low-grade glioma was diagnosed (astrocytoma, oligodendroglioma, or mixed glioma) were treated at the London Regional Cancer Centre in London, Ontario. All 80 underwent an initial surgical procedure ranging from biopsy sampling to gross-total resection. The patients who underwent gross-total resection did not receive radiotherapy, whereas 47 of the patients who underwent subtotal resection subsequently received this treatment (seven at the time of disease progression and 40 in the immediate postoperative period). Before 1970, there was a tendency to administer postoperative radiotherapy to all patients who underwent subtotal resection, but after 1970 the patient population receiving postoperative radiation treatment consisted primarily of those who were 4 years of age or older, who had undergone biopsy sampling or minor resections, and who had tumors of the optic tracts, hypothalamus, thalamus, or brainstem. Patients were selected for this volumetric study if they had received cranial radiation for residual or progressive low-grade glioma and if serial computerized tomography (CT) studies were available that demonstrated measurable residual tumor postoperatively, allowing objective tumor response assessment. Of 47 patients who received radiotherapy, 28 were excluded from analysis for the following reasons: 11 had nonmeasurable postoperative preradiotherapy tumor, in 13 no postoperative baseline CT scan had been obtained, and in four the scans were missing or unavailable.

Clinical information obtained from the patient's chart included age at diagnosis, sex, presenting symptoms and date of clinical presentation, estimated Karnofsky Performance Scale (KPS)[13] score, tumor location, date of surgery, type and extent of surgical resection, histological findings, radiotherapy details, progression of tumor and type of salvage therapy, last known disease status, and date of last known status. The extent of resection was estimated by comparing pre- and postoperative CT scans. Surgical resection consisted of a biopsy procedure in 12 patients, a minor resection ( $3 / 450 \%$ of tumor) in four patients, and a major resection (gt $50 \%$ of tumor) in three patients. Tumor response was estimated by measuring the three largest tumor dimensions of the contrast-enhancing abnormalities or the low attenuation volume in nonenhancing lesions, in the anteroposterior $\left(D_{1}\right)$, superoinferior $\left(D_{2}\right)$, and transverse views $\left(D_{3}\right)$. Tumor volumes on postoperative $C T$ scans obtained 
before and after radiotherapy were compared to assess volume response to radiation (volume $=1 / 2 / 6 \mathrm{D}_{1} \mathrm{D}_{2} \mathrm{D}_{3}$ ). Tumor volume response was classified as stable (1t $25 \%$ decrease), minor ( $>=25 \%$ to lt $50 \%$ decrease), major ( $>=50 \%$ decrease), or complete (no measurable tumor observed on follow-up scan).[15] Progressive disease was defined by an increase of $25 \%$ or more in tumor volume and/or recurrence proven by biopsy findings.

\section{RESULTS}

\section{Patient Demographics}

Demographic information for the 19 patients included in this study are presented in Table 1 . The median age for the 19 patients in the study was 10 years (range 3-17 years) at presentation. There were seven girls and 12 boys. Sixteen patients had astrocytomas, of which at least six were a pilocytic subtype and one was a pleomorphic xanthoastrocytoma, two patients had oligodendrogliomas, and one had a mixed glioma. All patients received focal radiotherapy, which was administered postoperatively. The median dosage was 5400 cGy in 30 fractions delivered to the isocenter. Computerized tomography scans obtained before and after radiotherapy and during the follow-up period were compared with the postoperative baseline CT scans.

\section{TABLE 1}

DEMOGRAPHIC AND CL NICAL CHARACTERISTISS OF PATIENTS WHO RECEIYED RT FOR LOW-GRADE GLIOMA

\begin{tabular}{|c|c|c|c|c|c|c|c|c|c|c|}
\hline $\begin{array}{l}\text { Case } \\
\text { No. }\end{array}$ & $\begin{array}{c}\text { Age at } \\
\text { RT (ys), } \\
\text { Sex }\end{array}$ & $\begin{array}{l}\text { Histological } \\
\text { Findngs }\end{array}$ & $\begin{array}{l}\text { Tumor } \\
\text { Location }\end{array}$ & Sugery & $\begin{array}{c}\text { PostfT } \\
\text { Respornse } \\
\text { onCT Scans }\end{array}$ & $\begin{array}{c}\% \\
\text { Resporse }\end{array}$ & $\begin{array}{l}\text { Time of } \\
\text { Maximum } \\
\text { Response }\end{array}$ & $\begin{array}{l}\text { Resporse } \\
\text { on Follow- } \\
\text { Up CT Scan }\end{array}$ & $\begin{array}{l}\text { Time } \\
\text { Period }\end{array}$ & $\begin{array}{c}\text { Present } \\
\text { Status }\end{array}$ \\
\hline $\begin{array}{l}1 \\
2\end{array}$ & & astro & frortal & subtodal & minor & $42 \%$ at $6 \mathrm{mos}$ & $6 \mathrm{mos}$ & major & $3 \mathrm{ys}^{\mathrm{s}}$ & $A w D$ \\
\hline 2 & $8, F$ & astro & brainstem & biopsy & stable & $47 \%$ at at $1 \mathrm{mo}$ & $8 \mathrm{mos}$ & not done & 3 mos & D of D \\
\hline & & $\begin{array}{l}\text { astoro, pl- } \\
\text { locytic }\end{array}$ & & Dlopsy & & $41 \%$ at at 1 mo & $8 \mathrm{mos}$ & $\begin{array}{l}\text { major re- } \\
\text { sponse }\end{array}$ & & \\
\hline 4 & $10, F$ & oligo & frortal & subtodal & major & $68 \%$ at $6 \mathrm{mos}$ & $6 \mathrm{mos}$ & stable & $6 y r^{3}$ & $A$ wil D \\
\hline 5 & $10, \mathrm{~m}$ & xartho & parietal & subtodal & stable & & & slow prog & $6 y^{3}$ & $A w^{\prime} D$ \\
\hline 6 & $4, F$ & oligo & brajnstem & biopsy & stable & & & stable & $5 \mathrm{ys}$ & $A w D$ \\
\hline 7 & $9, \mathrm{~m}$ & astro & optic & biopsy & stable & & & stable & $5 \mathrm{yrs}$ & $A w D$ \\
\hline 8 & $16, \mathrm{M}$ & astro & mi dbrain & biopsy & stable & & & stable & $4 y r s$ & $A w D$ \\
\hline 9 & $9, F$ & $\begin{array}{l}\text { astro, pi- } \\
\text { locytic }\end{array}$ & pons & biopsy & stable & & & $\begin{array}{l}\text { stable; } \\
\text { endarged } \\
\text { cyst }\end{array}$ & $\begin{array}{l}3 \mathrm{yrs} \\
4 \mathrm{yrs}\end{array}$ & $A w D$ \\
\hline 10 & 14. $\mathrm{M}$ & $\begin{array}{l}\text { astro, pi- } \\
\text { locytic }\end{array}$ & mi dbrain & biopsy & $\begin{array}{l}\text { stable, } \\
\text { enlarged } \\
\text { cyst }\end{array}$ & & & $\begin{array}{l}\text { slow prog } \\
\text { erlarged } \\
\text { cyst }\end{array}$ & $2 \mathrm{yrs}$ & $A w D$ \\
\hline 11 & $9, \mathrm{~F}$ & astro & pons & biopsy & stable & & & stable & $2 y / s$ & $A$ w \\
\hline 12 & 10. M & astro & thalam us & biopsy & stable & $100 \%$ at $5 \mathrm{ys}$ & $5 \mathrm{yrs}$ & complete & $5-8 \mathrm{ys}$ & $D$ of $D$ \\
\hline 14 & 3. & $\begin{array}{l}\text { astro } \\
\text { astro }\end{array}$ & $\begin{array}{l}\text { cerebellum } \\
\text { surasellar }\end{array}$ & $\begin{array}{l}\text { sutodal } \\
\text { suthodal }\end{array}$ & $\begin{array}{l}\text { stable } \\
\text { minor }\end{array}$ & $42 \%$ at $3 \mathrm{mos}$ & $1 \mathrm{wr}$ & Fuctuating & $3 \mathrm{gts}$ & $\begin{array}{l}A w D \\
A \& W\end{array}$ \\
\hline 15 & $13 \mathrm{~m}$ & astro & cerebellum & sutholal & stable & 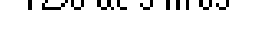 & 17 & stable & $8 \mathrm{ys}$ & $A w^{\prime} D$ \\
\hline 16 & $16 . \mathrm{M}$ & $\begin{array}{l}\text { astro, pi- } \\
\text { locytic }\end{array}$ & suprasellar & biopsy & major & $53 \%$ at 1 mo & $1 \mathrm{mo}$ & stable & 3 mos & $D$ of $D$ \\
\hline 17 & 5, $\mathrm{m}_{\text {locyt }}$ & astro, pi- & mi dbrain & biopsy & minor & $35 \%$ at 1 mo & $11 \mathrm{mos}$ & complete & $15 \mathrm{mos}$ & $A \& W$ \\
\hline 18 & $3, \mathrm{~m}$ & $\begin{array}{l}\text { mixed } \\
\text { glioma }\end{array}$ & suprasellar & suttodal & complete & $100 \%$ at $6 \mathrm{mos}$ & $6 \mathrm{mos}$ & complete & $6 \mathrm{yrs}$ & $A \& W$ \\
\hline 19 & $5, \mathrm{M}$ & $\begin{array}{l}\text { astro, pi- } \\
\text { locytic }\end{array}$ & mi dbrain & biopsy & minor & $25 \%$ at 1 mo & $1 \mathrm{mo}$ & stable & $10 \mathrm{~m} \omega$ & $A w D$ \\
\hline
\end{tabular}

A comparison of the study group of patients whose tumors responded to radiotherapy and the total population of patients with low-grade glioma is detailed in Table 2. The two groups displayed very similar characteristics except that, not surprisingly, more biopsy procedures than resections were performed among the 19 patients in the group studied. 

PED HTRIC POPULATION WITH LOW-GRADE GLIOMA

\begin{tabular}{|c|c|c|}
\hline Characteristic & $\begin{array}{l}\text { Study Gr oup } \\
\text { (19 pati ents) }\end{array}$ & $\begin{array}{l}\text { Total Population } \\
\text { (80 pati ents) }\end{array}$ \\
\hline $\operatorname{sen}(M / F)$ & $12: 7$ & $39: 41$ \\
\hline median age & 10 yrs & 7 yrs \\
\hline presentation (\%) & & \\
\hline seizure & 26 & 43 \\
\hline focal neurological de ficit & 47 & 60 \\
\hline \multicolumn{3}{|l|}{ tumor location (\%) } \\
\hline cerebral & 16 & 22 \\
\hline cerebellar & 10 & 28 \\
\hline Erainstem & 42 & 15 \\
\hline wentricular & 0 & 11 \\
\hline optic-hypothalamic & 21 & 17 \\
\hline thalamic & 11 & 7 \\
\hline \multicolumn{3}{|l|}{ histological findings (\%) } \\
\hline astrocytoma & 85 & 87 \\
\hline pilocytic subtype & 31 & 27 \\
\hline $\begin{array}{l}\text { oligodendrogliomatni sed glioma } \\
\text { resection (\%) }\end{array}$ & 15 & 13 \\
\hline gross total & 0 & 12 \\
\hline subtotal & 37 & 50 \\
\hline tiopsy & 63 & 37 \\
\hline \multicolumn{3}{|l|}{ owerall survival rate (\%) } \\
\hline $5-y$ & 94 & 83 \\
\hline $10-y r$ & 80 & 76 \\
\hline \multicolumn{3}{|l|}{ progression-free sur wi val rate $(\%)$} \\
\hline $5-y r$ & 88 & 77 \\
\hline $10-y r$ & 68 & 68 \\
\hline
\end{tabular}

\section{Tumor Response}

The median radiological follow-up period was 3.1 years, and the median clinical follow-up duration was 5.6 years. The first posttreatment scan was obtained at a median of 3.3 months (range 0-11 months) after completion of radiotherapy. An average of six follow-up CT studies (range 1-12 scans) were obtained in these patients. The mean pretreatment tumor volume was $17.1 \mathrm{~cm}^{3}$ (range $\left.0.5-42.1 \mathrm{~cm}^{3}\right)$, and the mean posttreatment volume was reduced to $11.5 \mathrm{~cm}^{3}$ (range $0-47.7 \mathrm{~cm}^{3}$ ). The mean volume decrease was $5.4 \mathrm{~cm}^{3}$ (range $0-40$ $\mathrm{cm}^{3}$ ), resulting in a mean $31 \%$ decrease. The maximum tumor response was judged as complete in four cases, major in four cases, minor in two cases, and stable in nine. Of the 10 patients with tumors that responded to radiotherapy, the maximum response was seen on the first follow-up scan in five. Five patients had protracted responses; their tumors continued to decrease in size between the end of radiation treatment, from 7 months to 5 years later. The mean time to maximum response for the 10 responders was 14.4 months.

No significant difference in histological findings, age of the patient, or estimated pretreatment KPS score was noted among responders compared with nonresponders in our small series of cases. The median age was 9.3 years for responders and 11.5 years for nonresponders. Seventy percent of responders had astrocytomas compared with $80 \%$ of the nonresponders. There were six patients with pilocytic astrocytomas and four of these were responders. The mean estimated pretreatment KPS score was 46 for responders and 50 for nonresponders.

\section{Clinical Outcomes}

The 10 -year actuarial survival rate was $80 \%$ for the 19 patients studied and $76 \%$ for the entire group, and the 10 -year disease-free survival rate was $68 \%$ for both groups. The Kaplan-Meier curves for actuarial and 
disease-free survival were not significantly different for the study group $(\mathrm{p}=0.52)$ than for the total group of 80 patients with low-grade gliomas $(\mathrm{p}=0.29)$.

Fifteen patients did not develop tumor progression. Nine of these 15 children demonstrated focal neurological deficits before receiving radiotherapy, and seven of these nine patients showed significant improvement of their focal neurological deficits despite the fact that only four of them were "responders" (had visible tumor reduction on serial imaging studies). Figure 1 comprises serial CT scans obtained in a child with a pilocytic astrocytoma whose tumor responded to radiation. Preradiation, the boy was hemiplegic and was confined to a wheelchair, but by 6 months postirradiation, his neurological examination was normal. However, clinical improvement in neurological function was not confined to responders only. Three of six patients with stable disease and no visible evidence of a change in tumor size on CT scans also demonstrated reversal of focal neurological deficits. All three patients with preirradiation cranial nerve deficits and one patient with corticospinal tract signs demonstrated complete reversal of their deficits during several months postirradiation. These patients have been followed for 5 years or more and have demonstrated stable tumor volume and no recurrence of neurological deficits. Seizure control secondary to radiotherapy could not be assessed independent of antiepileptic medication.

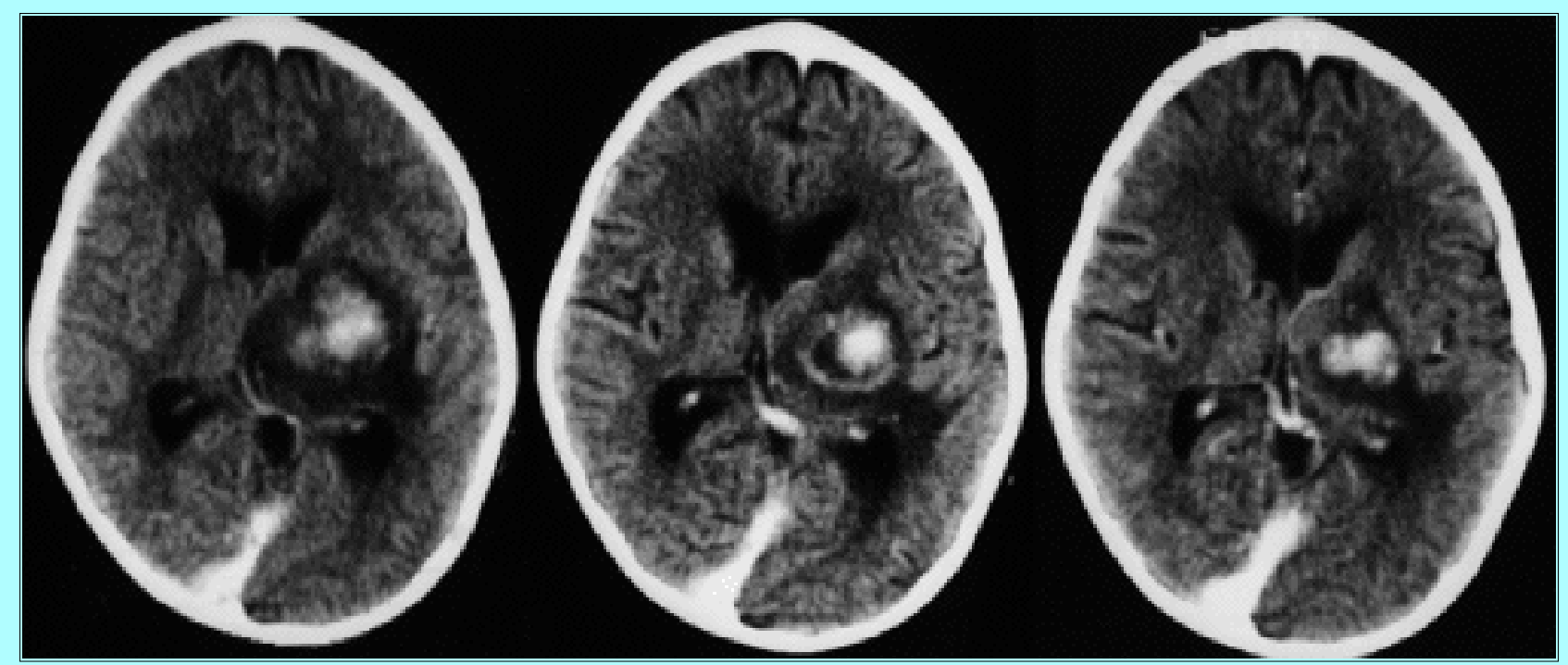

Fig. 1. Serial CT scans of a low-grade glioma demonstrating response to radiotherapy in an 8 -year-old boy who underwent stereotactically guided biopsy of a thalamic pilocytic astrocytoma. The histological diagnosis was confirmed at autopsy. Left: Axial CT scan obtained before radiotherapy. Center: Axial CT scan obtained 1 month after radiotherapy. Right: Axial CT scan obtained 6 months after radiotherapy.

\section{Local Tumor Control}

Four patients exhibited tumor progression after radiation treatment; the median interval was 2.5 years. Two of these patients developed enlargement of the cystic component of their tumors only. In one of these cases, the tumor itself showed a minimal reduction in size at 2 years postirradiation and in the other the tumor remained stable postradiotherapy. Four patients died, three as a result of tumor progression and one secondary to an infection.

\section{DISCUSSION}

We have encountered a number of difficulties in assessing the value of radiotherapy in the management of low-grade gliomas in children. The long natural history, particularly of pilocytic astrocytomas, makes the value of radiotherapy difficult to define. The radiographically determined response of low-grade gliomas to radiotherapy has not been well documented because it has been assumed that low-grade gliomas in children are 
indolent and unresponsive to radiotherapy, as assessed by tumor shrinkage. On the basis of our CT scan analysis, we suggest that low-grade gliomas in children can demonstrate shrinkage on radiographic studies in response to radiotherapy, but that such shrinkage is not directly related to tumor control or necessarily to improvement of symptoms. Forty-seven percent of the tumors studied exhibited a volume reduction of $25 \%$ or more following radiation treatment. Our study also demonstrated that response to radiation, when it occurred, was not always evident on the first follow-up scan obtained after radiation treatment. Although the group studied is a highly selected one, comparison of the overall survival rates in this group from the time of radiotherapy demonstrated no significant difference in comparison with the larger pediatric population with low-grade glioma from which it was drawn.

Confounding factors in the assessment of tumor volume changes include resolution of postoperative changes and steroid administration. In this particular study the majority of patients had contrast-enhancing tumors, which made the distinction between tumor and edema or hemorrhage more reliable. Also, the majority of patients had undergone biopsy procedures as opposed to resections, minimizing the probability that major postoperative changes would occur. The time to maximum tumor response was quite long (mean 14.4 months). In relation to this time frame, postoperative changes and steroid administration tended to be more short-term events for these children.

Patient age,[2,6,8] extent of resection,[6,21] tumor grade,[3] tumor location,[8,14,16,18] and radiation dosage[6] have been reported to be variables having prognostic significance in low-grade gliomas, but response to radiation has never been examined as a prognostic factor in this patient group. However, chemotherapeutic agents are often evaluated in terms of response rates. Packer, et al.,[19] have reported their response rate findings after using chemotherapy to treat low-grade gliomas, noting that 23 of 37 patients with low-grade glioma who were newly diagnosed as diencephalic and 12 of 23 patients with recurrent disease experienced a $50 \%$ or greater reduction in tumor volume. Gajjar, et al.,[7] reported a response rate to chemotherapy of 57\% in 14 children with progressive low-grade gliomas, although it is not known whether response to chemotherapy correlates with improved survival. Over the follow-up period for our patient group, $47 \%$ of the tumors responded to radiation, with $44 \%$ demonstrating a $50 \%$ or greater volume reduction over time.

Regarding malignant gliomas in adults, several authors[1,4,9] have reported response rates of 30 to $40 \%$ but there is controversy as to whether response rates translate into longer survival times.[9] Eyre, et al.,[5] examined the response rates of subtotally resected low-grade gliomas in adults. They defined response as an improvement in neurological function together with a $50 \%$ or greater decrease in the product of the largest perpendicular tumor diameters on CT scans and found these to be moderately radioresponsive lesions, with a $63 \%$ response rate in 54 tumors. In contrast, in our study of low-grade gliomas in children, there was a fairly even ratio between those tumors that did not respond to radiation but remained stable in size and those that shrank, either immediately or over time. Response, when it occurred, was very slow, taking years in many cases, but was usually demonstrable to some extent on the postradiation scan. The majority of patients continued to display visible residual tumor on CT scans for many years after therapy: only four of the patients achieved a complete response. Other types of central nervous system tumors, such as meningiomas and pituitary adenomas, tend to have a similar pattern of very slow, minimal response to radiation but very high long-term control rates.[10] Conversely, some radioresponsive tumors such as central nervous system lymphomas recur rapidly. Therefore, tumor shrinkage may not be the only or most important measure of tumor control. Prospective studies in which tumor response is evaluated might be made more meaningful by the inclusion of information about disease-free survival or symptom improvement.

The radiotherapeutic management of subtotally resected low-grade gliomas is even more controversial in children than in adults because progression-free survival rates tend to be higher and cognitive and endocrine effects more significant. Some authors have reported higher survival rates with the addition of postoperative radiotherapy,[17] whereas others have not confirmed a survival benefit.[20,21] Pollack, et al.,[21] reported 
actuarial survival rates at 5,10 , and 20 years of $95 \%, 93 \%$, and $85 \%$, respectively, in 71 patients with low-grade gliomas; no significant survival difference was conferred by the addition of radiotherapy. Studies of radiotherapy in the treatment of pediatric low-grade gliomas have tended to focus on prolongation of survival as an endpoint while ignoring other potential benefits such as tumor response and symptom improvement. The management trend for low-grade gliomas in children (particularly with the increasing use of chemotherapy) is toward deferral of radiation treatment because of its toxicity and the lack of a conclusive survival benefit. However, as radiation delivery becomes more conformal because of techniques such as fractionated stereotactic radiosurgery or three-dimensional planning, and because there is some evidence that lower radiation doses may be equally effective,[12] the long-term risks of this treatment may well be reduced and the risk/benefit ratio may then have to be reanalyzed. Such an analysis should include assessments of tumor response and symptom improvement as well as survival rates. Results from our small series indicate that radiation may offer benefits in terms of tumor reduction and symptom improvement, leading us to suggest a continuing role for radiation, particularly in unresectable or symptomatic tumors, independent of the survival issue.

Although tumor response did not correlate directly with patient survival, such a relationship would be difficult to identify because of the very high rate of control of these tumors following radiation treatment. What is clear is that symptomatic improvement of neurological deficits did occur in the majority of patients who received radiotherapy, independently of tumor response. Rogers, et al.,[22] have previously reported reduced seizure frequency in medically intractable epilepsy in patients with low-grade glioma treated with cranial radiation.

\section{CONCLUSIONS}

This retrospective review of radiographically demonstrated tumor response shows that pediatric low-grade gliomas in children can be radioresponsive but that the decrease in size is often slow (mean time to maximum response 14.4 months). No clinical correlation could be demonstrated; stability and shrinkage after radiotherapy were both correlated with long-term control. Symptomatic improvement of focal neurological deficits may occur independently of radiation response, indicating that radiation should continue to play a role in the treatment of symptomatic tumors. Tumor response and symptom reduction should be examined along with survival and long-term side effects in future studies involving radiation treatment of low-grade gliomas in children, particularly as radiation techniques become increasingly uniform.

\section{Acknowledgments}

The authors thank Joanne Pelletier for assistance in retrieving scans, and Vickey McAlpine and Mary-Ellen Coughlin for typing the manuscript.

\section{References}

1. Barker FG II, Prados MD, Chang SM, et al: Radiation response and survival time in patients with glioblastoma multiforme. J Neurosurg 84:442-448, 1996

2. Bloom H: Treatment of brain gliomas in children, in Bleehen NM (ed): Tumours of the Brain. Berlin: Springer-Verlag, 1986, pp 12-40

3. Butler D, Jose B, Summe R, et al: Pediatric astrocytomas. The Louisville experience: 1978-1988. Am J Clin Oncol 17:475-479, 1994

4. Curran WJ, Scott CB, Yung WKA, et al: Imaging response is highly predictive of survival of malignant glioma patients treated with standard or hyperfractionated RT and carmustine in RTOG 9006. Int J Radiat Oncol Biol Phys 36 (Suppl):160, 1996 (Abstract)

5. Eyre HJ, Crowley JJ, Townsend JJ, et al: A randomized trial of radiotherapy versus radiotherapy plus CCNU 
for incompletely resected low-grade gliomas: a Southwest Oncology Group study. J Neurosurg 78:909-914, 1993

6. Freeman CR, Suissa S: Brain stem tumors in children: results of a survey of 62 patients treated with radiotherapy. Int J Radiat Oncol Biol Phys 12:1823-1828, 1985

7. Gajjar A, Heideman RL, Kovnar EH, et al: Response of pediatric low-grade gliomas to chemotherapy. Pediatr Neurosurg 19:113-120, 1993

8. Gajjar A, Sanford RA, Heideman R, et al: Low-grade astrocytoma: a decade of experience at St. Jude's children's research hospital. J Clin Oncol 15:2792-2799, 1997

9. Gaspar LE, Fisher BJ, Macdonald DR, et al: Malignant glioma--timing of response to radiation therapy. Int J Radiat Oncol Biol Phys 25:877-879, 1993

10. Goldsmith BJ, Wara WM, Wilson CB, et al: Postoperative irradiation for subtotally resected meningiomas. A retrospective analysis of 140 patients treated from 1967 to 1990. J Neurosurg 80:195-201, 1994

11. Horwich A, Bloom HJG: Optic gliomas: radiation therapy and prognosis. Int J Radiat Oncol Biol Phys 11:1067-1079, 1988

12. Karim ABM, Maat B, Hatlevoll R, et al: A randomized trial on dose-response in radiation therapy of low-grade cerebral gliomas. European Organization for Research and Treatment of Cancer (EORTC) Study 22844. Int J Radiat Oncol Biol Phys 36:549-556, 1996

13. Karnofsky DA, Burchenal JH: The clinical evaluation of chemotherapeutic agents in cancer, in MacLeod CM (ed): Evaluation of Chemotherapeutic Agents. New York: Columbia University Press, 1949, pp 191-205

14. Littman P, Jarrett P, Bilaniuk LT, et al: Pediatric brain stem gliomas. Cancer 45:2787-2792, 1982

15. Macdonald DR, Cascino TL, Schold SC, et al: Response criteria for phase II studies of supratentorial malignant glioma. J Clin Oncol 8:1277-1280, 1990

16. Mantravadi RVP, Phatak R, Bellur S, et al: Brain stem gliomas: an autopsy study of 25 cases. Cancer 49:1294-1296, 1982

17. Marsa GW, Probert JC, Rubenstein LJ, et al: Radiation therapy in the treatment of childhood astrocytic gliomas. Cancer 32:646-655, 1973

18. Matson DD: Neurosurgery of Infancy and Childhood, ed 2. Springfield, Ill: Charles C Thomas, 1969

19. Packer RJ, Lange B, Ater J, et al: Carboplatin and vincristine for recurrent and newly diagnosed low-grade gliomas of childhood. J Clin Oncol 11:850-856, 1993

20. Packer RJ, Savino PJ, Bilaniuk LT, et al: Chiasmatic gliomas of childhood. A reappraisal of natural history and effectiveness of cranial irradiation. Childs Brain 10:393-403, 1983

21. Pollack IF, Claassen D, Al-Shboul Q, et al: Low-grade gliomas of the cerebral hemispheres in children: an analysis of 71 cases. J Neurosurg 82:536-547, 1995

22. Rogers LR, Morris HH, Lupica K: Effect of cranial irradiation on seizure frequency in adults with low-grade astrocytoma and medically intractable epilepsy. Neurology 43:1599-1601, 1993

23. Schultz CJ, Geard CR: Radioresponse of human astrocytic tumors across grade as a function of acute and chronic irradiation. Int J Radiat Oncol Biol Phys 19:1397-1403, 1990 
Manuscript received June 11, 1997.

Accepted in final form December 10, 1997.

Address reprint requests to: Barbara J. Fisher, M.D, London Regional Cancer Centre, 790 Commissioners Road East, London, Ontario, N6A 4L6 Canada. 